\title{
A EFETIVIDADE NA FASE DE EXECUÇÃO TRABALHISTA ATRAVÉS DO EXERCíCIO DA LEGITIMIDADE ATIVA PELO JUIZ
}

\author{
Fernanda Teodoro da Silva; Francislaine de Almeida Coimbra Strasser \\ Universidade Do Oeste Paulista-UNOESTE, Presidente Prudente, SP. E-mail: fernanda.teodoro@outlook.com
}

\begin{abstract}
RESUMO
Pela nova roupagem constitucional, a lei deve se subordinar aos princípios constitucionais da justiça e aos direitos fundamentais, de modo que a tarefa do operador do direito deixa de ser simplesmente à subsunção à lei, para compreendê-la à luz da Constituição Federal e dos princípios. Pretende-se neste artigo abordar a aplicabilidade dos princípios, inclusive da inércia e da legitimidade processual na execução trabalhista, em especial, no que se refere à celeridade e efetividade no âmbito jurídico. A metodologia aplicada foi à dialética-dedutiva, com pesquisa bibliográfica, doutrina e jurisprudência. Isso porque após a sentença transitada em julgado, nada obsta ao magistrado em impulsionar à execução trabalhista de ofício, seja pela natureza alimentar dos créditos trabalhistas, seja pela condição de maior vulnerabilidade do trabalhador. Conclui-se, que o princípio da inércia jurisdicional deve ser relativizado permitindo a ampla legitimidade ex officio do juízo para a promoção da execução trabalhista.
\end{abstract}

Palavras chaves: Princípios; Direito do trabalho; Execução; Celeridade; Inércia Jurisdicional.

\section{EFFECTIVENESS IN THE PHASE OF LABOR EXECUTION FOR LEGITIMIDADE ASSETS EXERCISE FOR JUDGE}

\section{ABSTRACT}

The proposed new constitutional rule, shoulb be in line with the principles and the human rights, thats why the legal pratic task ceases to be obey the Law geared toward to comply the principles and the Federal Constitutional. The methodology used was the deduct dialetic with bibliographical research, doctrine and jurisprudence. So the proposal of this article is to discuss aspects related to principles applied to labor enforcement, especially the Law of inertia anda legality. Means that, once the right is recognized, there is nothing to prevent the magistrate, himself, from promoting the execution, whether the human labour condition, whether the nature nuture of monies labour. It's concluded that despite the importance of the principle of jurisdictional inertia, this should be relativized allowing the ex officio legal legitimacy of the court to promote labor enforcement.

Keywords: Principles - Labor law - Enforcement - Speed - Jurisdictional nertia 


\section{INTRODUÇÃO}

Quando uma pessoa recorre ao Poder Judiciário, busca obter dentro de um prazo razoável uma tutela jurisdicional justa e efetiva. E quando esse direito decorre de uma obrigação que dá ensejo a uma verba de caráter alimentar, é compreensivo que a parte demandante busque a satisfação da lide de forma mais célere.

Para isso, o processo deve seguir a forma prescrita em lei, além do preenchimento das condições da ação, pressupostos processuais e outros princípios gerais do direito de igual relevância.

Como se não bastasse, quando se ajuíza uma ação em uma Justiça Especializada, como a Justiça Laboral, outras regras processuais também são observadas, como o princípio da simplicidade, que permite mais flexibilidade, buscando facilidade ao acesso à justiça, bem como na prestação jurisdicional, prezando pelo não formalismo.

Justifica-se essa particularidade pela natureza alimentar dos créditos trabalhistas, fundamentais a subsistência do exequente. Ademais, diferente da execução civil, em que hipossuficiente é o devedor, no processo do trabalho, o credor apresenta-se em condição de maior vulnerabilidade, o que exige a concretização dos princípios da Celeridade e da Efetividade da tutela executiva.

\section{METODOLOGIA}

O presente estudo seguirá o método dialético-dedutivo, com emprego de pesquisa à legislação, doutrina e jurisprudência acerca da matéria objeto da investigação.

\section{DO PRINCÍPIO DA INÉRCIA E A LEGITIMIDADE PROCESSUAL}

Os princípios fundamentais, conforme leciona Marcos Vinicius Rios Gonçalves (2016, p. 64) nada mais são que "premissas sobre os quais se apoiam as ciências". Portanto, são diretrizes gerais ao ordenamento jurídico.

Dessa forma, com a natureza jurídica de serem vigas mestras do ordenamento jurídico, devem evoluir à medida que a sociedade também evoluir, sob pena de permanecerem engessados e não cumprirem com essa função singular.

Nesse sentido lecionam Marinoni; Arenharti e Metidieiro:

Os princípios expressam concepções e valores que estão indissociavelmente ligados ao ambiente cultural. Mas, como a sociedade evolui paulatinamente, os princípios devem ser redimensionados nessa mesma intensidade e velocidade. Não fosse assim, seria falso que o princípio adquire substantividade a partir do seu contato com a realidade. Aliás, se o conteúdo dos princípios não sofresse mutação com o tempo, a Constituição restaria engessada à letra das suas normas ou à interpretação que um dia a elas foi conferida. (MARINONI; ARENHARTI; METIDIEIRO, 2017, p. 44).

No que tange ao princípio da Inércia Processual ou da Jurisdição, ele está disposto no artigo 2으 do Código de Processo Civil Brasileiro, em que: "o processo começa por iniciativa da parte e se desenvolve por impulso oficial, salvo as exceções previstas em lei". (BRASIL, 2015).

Para que seja iniciado o processo é necessário que a parte interessada ingresse com a demanda, invocando assim, uma resposta do Judiciário.

Isso significa que, ainda que alguém seja detentor de um direito, o magistrado somente prestará a tutela jurisdicional uma vez provocado, impondo-se, por conseguinte, a apresentação do pedido pelo interessado. 
De acordo com a doutrina de Sá; Freire (2012, p.26): "por outras palavras, o processo não se inicia ex officio (de ofício), sem requerimento. Ne procedat judex ex officio (não proceda o juiz de ofício) ou nemo judex sine actore (ninguém é juiz sem autor)".

Assim, o juiz fica limitado à iniciativa da ação, que depende das partes, bem como aos pedidos pleiteados na peça processual, que não pode extrapolar os fundamentos apresentados pelas partes.

Mas qual seria a parte interessada processualmente?

Entende-se como interessado aquele que seja titular do direito líquido e certo violado ou com justo receio de violação, esse então, terá a legitimidade ativa para propor a ação. Segundo Carlos Bezerra Leite:

$\mathrm{O}$ art. 3o do $\mathrm{CPC} / 73$ dispunha que "para propor ou contestar a ação é necessário ter interesse e legitimidade". Tal regra foi revogada pelo art. 17 do NCPC, in verbis: "Para postular em juízo é necessário ter interesse e legitimidade". Andou bem o legislador do NCPC, porquanto o termo postular tem significado mais amplo. Destarte, não apenas para propor ou contestar, como também para reconvir, intervir como terceiro ou formular qualquer postulação no decorrer do processo, é preciso ter legitimidade e interesse. (LEITE, 2017, p.1789):

Nesse sentido, fica evidente que além das partes envolvidas diretamente na lide, poderá ter legitimidade ativa ou passiva, terceiros que sejam interessados em sua resolução.

$\mathrm{Na}$ seara trabalhista, entende-se como parte legítima a ingressar com reclamação trabalhista, aquele que, sendo empregado ou empregador, compreende que tem seu direito prejudicado.

A legitimidade ativa para propor a ação ou reclamação refere-se à fase inicial do processo, quer seja, a também chamada de fase de conhecimento.

E que, após a fase de conhecimento, conforme lecionam Miessa e Correia (2017), que, após a fase de conhecimento, tendo logrado êxito a parte ativa, iniciará a fase de execução.

No entanto, ainda que essa seja a máxima no processo, inclusive no âmbito trabalhista, há exceções no que se refere à legitimidade ativa.

Isso porque, a legitimidade ativa poderá, em determinados casos, ser extraordinária, na qual, alguém, não possuidor do direito, poderá pleiteá-lo. De acordo com SÁ; Freire (2012, p. 144): Já a legitimidade é uma aptidão específica para agir em juízo ante determinada situação concreta. É conferida aos titulares da relação jurídica material hipotética, também conhecida como relação jurídica Oafirmada, esquema abstrato ou situação legitimante. Difere a legitimidade para a causa da legitimação extraordinária, porque esta é conferida por lei - pelo sistema jurídico - a quem não é titular da relação jurídica material hipotética.

A legitimação extraordinária poderá ocorrer, por exemplo, na fase executória da ação trabalhista, onde o juiz, que não compõe nenhum dos polos da ação, poderá dar início à execução de ofício.

Aliás, ainda que o magistrado não seja a parte interessada na lide e, por consequência do princípio da Inércia Processual e, da Imparcialidade, é preferível que quaisquer impulsos ao processo sejam realizados pelas partes. No entanto, em razão de outros princípios como o da Efetividade da Execução e Celeridade do Processo, é cabível, mesmo que em exceção, que o magistrado realize atos processuais de ofício.

No âmbito trabalhista, de acordo com o disposto no artigo 878, que sofreu alteração após a reforma trabalhista, Lei no 13467/2017, (BRASIL, 2017), a execução será promovida pelas partes, permitida a execução de ofício pelo juiz ou pelo Presidente do Tribunal apenas nos casos em que as partes não estiverem representadas por advogado. 
De modo que, em caráter excepcional, será permitida a execução de ofício pelo juiz, como pode ser observado num trecho retirado da decisão da 7a Turma do Tribunal Regional da 2a Região, publicada em 12 de julho de 2018, em que restou afastada a prescrição intercorrente ao exequente, uma vez que a execução poderia ter sido realizada de ofício pelo juiz. Nesse sentido:

(...) com efeito, o artigo 878 da Consolidação de clareza solar ao estipular que dentre outras formas, a execução trabalhista será promovida "ex officio" pelo próprio Juiz. Destarte, desde o surgimento da Consolidação das Leis do Trabalho no mundo jurídico, tão conhecido o princípio do impulso oficial nas execuções trabalhistas. Não por outro motivo que a mais alta Corte Trabalhista do país editou a Súmula no 114, no sentido de que "É inaplicável na Justiça do Trabalho a prescrição intercorrente". Pelo mesmo motivo, não há falar-se em aplicação subsidiária do Código de Processo Civil, pois se a execução pode ser promovida "ex officio", por expressa disposição legal (artigo 878 da CLT) torna-se incompatível, lógica e juridicamente, a aplicação da prescrição intercorrente. (TRT-2 00918004419945020033 SP, Relator: JOSE CARLOS FOGAÇA, 7ạ Turma - Cadeira 2, Data de Publicação: 12/07/2018).

No caso em tela, a parte que recorreu da decisão justificou a sua inércia em executar os créditos trabalhistas por não ter encontrado uns dos executados, contudo, ainda que os porquês não venham ao caso nesse momento, é de suma importância refletir o quão benéfico e eficiente pode ser o impulsionamento do magistrado nesses acontecimentos.

Num caso análogo, pôde ser verificado os benefícios da execução de ofício por parte do magistrado, cujo Tribunal Regional do Trabalho da 2으 região afastou a prescrição intercorrente, pois ficou comprovado que o autor sequer havia sido intimado dos atos processuais. Nesse sentido:

E M E N T A - PRESCRIÇÃO INTERCORRENTE. A Súmula 114 do C. TST está calcada no fato de que a execução, no processo do trabalho, pode (deve) ser impulsionada pelo Juiz, ex officio. Entretanto, a execução, não raro, depende de atos que só o autor pode praticar. Em tais hipóteses a omissão e negligência não podem servir de fundamento para a eternização da execução, o que é uma clara afronta à necessidade da segurança jurídica, como fator imprescindível para a paz social. Por isso, à vista do que dispõem os artigos 878 da CLT e 40 da Lei 6.830/80, entende-se que a prescrição intercorrente tem lugar apenas na hipótese de paralisação do processo por culpa exclusiva do autor. No caso, o autor sequer foi intimado acerca do despacho de fls. 170, que determinava que os autos aguardassem no arquivo provisório a provocação do exequente. Da mesma forma, não houve qualquer decisão posterior do MM. Juízo de origem e no sentido de ser aplicada a penalidade de extinção da execução, caso o demandante não promovesse atos para o respectivo prosseguimento. Assim, nada obstante os argumentos acima acerca da aplicabilidade da prescrição intercorrente na Justiça do Trabalho, entendo que não se pode atribuir à exequente referida penalidade, quando não lhe é dada a oportunidade de se manifestar acerca desse ato, ante à inexistência de decisão e intimação para tanto. Agravo de Petição a que se dá provimento. (TRT-2 03215005719975020201 Barueri - SP, Relator: ODETTE SILVEIRA MORAES, Data de Julgamento: 23/01/2018, 11a Turma, Data de Publicação: 30/01/2018).

No mesmo sentido, o Enunciado № 113 da 2으 Jornada de direito material e processual do trabalho:

Em razão das garantias constitucionais da efetividade, da duração razoável do processo e em face da determinação constitucional da execução de oficio das contribuições previdenciárias, parcelas estas acessórias das obrigações trabalhistas, o artigo 878 da CLT deve ser interpretado conforme a Constituição, de modo a permitir a execução de ofício dos créditos trabalhistas, ainda que a partes esteja assistida pelo advogado. (ANAMATRA, 2018). 
Reitere-se que na acertada decisão supra, dispõe que a prescrição intercorrente é conhecida quando ocorre a paralisação do processo em decorrência da culpa exclusiva do exequente.

Isso porque, sabe-se que no direito, é imprescindível o respeito aos prazos processuais, até mesmo em razão da celeridade processual.

Contudo, em se tratando de uma verba de caráter alimentar, como a trabalhista, há que se ter cautela jurídica ao decretar a prescrição intercorrente, mesmo porque vigora o modelo cooperativo no processo, que encontra substrato no objetivo fundamental da solidariedade, previsto o artigo 3ㅇ, I da Constituição Federal de 1988, (BRASIL, 1988) servindo como meio na consecução do Estado Democrático de Direito, uma vez que este possui como principal característica a prévia participação de todos.

Ademais, conforme leciona Marcos Vinicius Rios Gonçalves (2016, p.94):

Vem expressamente consagrado no art. $6^{\circ}$ do CPC: "Todos os sujeitos do processo devem cooperar entre si para que se obtenha, em tempo razoável, decisão de mérito justa e efetiva". Constitui desdobramento do princípio da boa-fé e da lealdade processual. Mas vai além, ao exigir, não propriamente que as partes concordem ou ajudem uma à outra -já que não se pode esquecer que há um litígio entre elas -,mas que colaborem para que o processo evolua adequadamente. Um exemplo concreto é aquele fornecido pelo art. 357, $\S 3^{\circ}$, que trata do saneamento do processo. Em regra, ele é feito pelo juiz, sem necessidade da presença das partes. Mas, se a causa apresentar complexidade em matéria de fato ou de direito, o juiz deverá convocar. audiência, para que o saneamento seja feito em cooperação com as partes, oportunidade em que, se for o caso, ele as convidará a integrar ou esclarecer suas alegações.

Desse modo, o novel artigo 878 da CLT, mencionado, deve ser adequadamente interpretado, sendo incapaz de restringir o impulso oficial do juiz na fase executiva, ainda que a parte esteja assistida por advogado, viabilizando todos os atos fundamentais à efetivação da execução.

\section{PRINCÍPIO DA CELERIDADE PROCESSUAL EM FASE DE EXECUÇÃO}

É cediço que o processo deve estender-se por um período razoável, eis que assim, deve ser respeitado o princípio constitucional da Duração Razoável do Processo, expresso no artigo 50, LXXVIII da Carta Magna. (BRASIL, 1988).

Em relação aos princípios constitucionais e aos diretamente ligados ao processo em modo geral, Filho (2016, p. 22), dispõe:

A Reforma do Judiciário, realizada no ano de 2004, incorporou o inciso LXXVIII ao art. 5.ㅇ da CF, com a seguinte redação: "a todos, no âmbito judicial e administrativo, são assegurados a razoável duração do processo e os meios que garantam a celeridade de sua tramitação", positivando o princípio da razoável duração do processo na Carta Magna. Entendemos que a razoável duração do processo somente é possível, em termos reais e concretos, com a aprovação de normas que desburocratizem o CPC, sob pena de o princípio constitucional se tornar letra morta.

E ainda, o princípio da Celeridade Processual, também encontra respaldo no artigo 765 da CLT, que assim dispõe: "Os Juízos e Tribunais do Trabalho terão ampla liberdade na direção do processo e velarão pelo andamento rápido das causas, podendo determinar qualquer diligência necessária ao esclarecimento delas". (BRASIL, 1943).

Em consoante com o artigo 765 da CLT, Leite (2017, p. 597), em sua obra, exemplificou uma possibilidade de o magistrado dar impulso ao processo: 
Na fase de execução (ou cumprimento) da sentença trabalhista que contenha obrigação pecuniária, pensamos que, por força da interpretação sistemática dos arts. 20, § 20, $448 \mathrm{e}$ 878 da CLT, o juiz do trabalho tem o poder-dever de promover a execução, desconsiderando, de ofício, a personalidade jurídica da empresa executada, tanto nas hipóteses em que verificarem a inexistência ou insuficiência de bens da empresa executada quanto nos casos de fraude ou abuso dos sócios.

O princípio da Celeridade Processual corrobora diretamente com outro, o princípio da Efetividade Processual e, além disso, pode-se dizer que ambos os princípios estão ligados ao acesso à justiça.

O referido princípio encontra também respaldo no artigo 4으 do Código de Processo Civil, instituído pela Lei $13.105 / 2015$, que regulamenta: "As partes têm o direito de obter em prazo razoável a solução integral do mérito, incluída a atividade satisfativa". (BRASIL, 2015).

\section{DO PRINCÍPIO DA EFETIVIDADE}

O processo precisa cumprir seu papel fundamental que, de forma sucinta, seria a prestação jurisdicional. E, assim sendo, é de suma importância que ele seja efetivo.

Destarte, não é interessante que o curso processual seja célere, mas não atinja seu objetivo de forma positiva. É imprescindível que não tenha somente uma duração razoável, mas que quando findo, seu resultado seja satisfatório.

A efetividade do processo depende de como são realizados os atos processuais, sem correlação com determinada fase processual. Contudo, na fase de execução de sentença, faz-se mister a efetividade.

Isso porque, a tutela jurisdicional já está sendo prestada e o direito reconhecido em um título executivo judicial. Nesse sentido, já há um resultado, que prima pela satisfação. É o que em outras palavras afirma Lima (2015, p. 432):

A ação de execução, por sua vez, parte da premissa de que a certeza do direito já está fixada, consubstanciada em um título executivo. Tal título pode ter natureza judicial (a sentença de condenação) ou extrajudicial (um documento ao qual a lei atribua força executiva). O exequente busca, mediante atos de constrição sobre o patrimônio do devedor ou, excepcionalmente, sobre o próprio devedor, como se dá na execução de alimentos, a satisfação material da obrigação, independentemente da vontade do adversário.

Desse modo, com base nos princípios supracitados é relevante que se utilize de instrumentos, como o da execução ex officio, visto que através dela, pode-se encontrar o remédio capaz de conferir de fato, o exercício efetivo do direito do jurisdicionado.

\section{CONCLUSÃO}

O presente artigo objetivou realizar uma breve análise da fase executória na área trabalhista, à luz de alguns dos princípios norteadores do direito processual civil, do trabalho e, também, constitucional.

Observou-se que após o advento da Lei 13.467/2017, que reformou alguns pontos da Consolidação das Leis do Trabalho, o magistrado apenas dará início a execução de ofício se as partes não tiverem advogado constituído. Apesar disso, é importante salientar que não se deve aceitar a aplicação literal do dispositivo, pois senão acabaria com o princípio inquisitivo na fase executiva, restringindo a atuação oficiosa do órgão jurisdicional, o que feriria com as garantias constitucionais da efetividade e da duração razoável do processo. 
Conclui-se, que no máximo o artigo 878 da CLT deve impedir o início da fase executiva da sentença condenatória da obrigação de pagar, viabilizando-se, por exemplo, a expedição de ofícios para a localização do executado, penhora de bens, ou seja, a realização de atos fundamentais à efetividade da execução.

Assim, não incentivaria os inadimplentes e tão pouco as rotas de fuga, pois bastaria que o devedor se esquivasse por dois anos para obter como recompensa o "perdão da dívida".

Dessa forma, a melhor interpretação a ser feita, em consonância com o ordenamento jurídico é a de permitir a execução de ofício dos créditos trabalhistas, ainda que a parte esteja assistida por advogado pela natureza alimentar a que se revestem.

\section{REFERÊNCIAS}

ANAMATRA. Associação Nacional dos Magistrados da Justiça do Trabalho. Enunciados aprovados na 2a Jornada de Direito Material e Processual do Trabalho. Brasília, 27 fev. 2018. Disponível em: <https://www.anamatra.org.br/imprensa/noticias/26227-enunciados-aprovados-na-2-jornada-dedireito-material-e-processual-do-trabalho-sao-organizados-por-tema> Acesso em: 08 ago. 2018.

BRASIL, CÓDIGO DE PROCESSO CIVIL. Código de Processo Civil Brasileiro. Brasília: Senado Federal, 2.015 .

BRASIL, CONSTITUIÇÃO (1.988). Constituição da República Federativa do Brasil. Brasília: Senado Federal, 1.988.

BRASIL. Consolidação das Leis do Trabalho. Decreto-Lei, n.o 5452, de 1 de maio de 1943. Das Normas Gerais da Tutela do Trabalho. In Vade Mecum. JusPodivm: 2018.

BRASIL. Lei no 13467/2017, de 11 de novembro de 2017. Altera a Consolidação das Leis do Trabalho. Disponível em: <http://www2.camara.leg.br/legin/fed/lei/2017/lei-13467-13-julho2017-785204-publicacaooriginal-153369-pl.html> Acesso em: 12 set. 2018.

BRASIL. Tribunal Regional do Trabalho (2. Região), 00918004419945020033 São Paulo, Relator: JOSE CARLOS FOGAÇA, 7ạ Turma - Cadeira 2, Data de Publicação: 12 jul. 2017. Disponível em: $<$ https://trt-2.jusbrasil.com.br/jurisprudencia/600457539/918004419945020033-sp/inteiro-teor600457549?ref=juris-tabs> Acesso em: 08 ago. 2018.

BRASIL. Tribunal Regional do Trabalho (2. Região), Barueri - SP, Relator: ODETTE SILVEIRA MORAES, Data de Julgamento: 23/01/2018, 11a Turma, Data de Publicação: 30 jan. 2018, Disponível em https://trt-2.jusbrasil.com.br/jurisprudencia/510451158/516002820095020434santo-andre-sp/inteiro-teor-510451173?ref=juris-tabs / Acesso em: 08 ago. 2018.

FILHO, M. M. Curso de Direito Processual Civil, 12a ed. São Paulo: Atlas, 2016.

GOLÇALVES, Marcus Vinicius Rios. Direito Processual Civil Esquematizado - 7. Ed. - São Paulo: Saraiva, 2016;

LEITE, Bezerra, C. H. Curso de Direito Processual do Trabalho, 15a ed. São Paulo: Saraiva, 2017.

LIMA, F.A.N, Teoria Geral do Processo Judicial-2. ed. São Paulo: Atlas, 2015. 
MARINONI, Luis Guilherme; ARENHART, Sergio Cruz; MITIDIERO, Luiz. Novo Curso de Processo Civil. Teoria de Processo Civil.- 3. Ed, São Paulo: Revista dos Tribunais, 2017.

MIESSA, Elisson; CORREIA, Henrique. Manual da Reforma Trabalhista, Salvador: Editora JusPodivm, 2018.

SÁ, de., R. M., FREIRE, Lima., R.D. C.,Col. saberes do direito 22 - Processo Civil I : teoria geral do processo, 1a Ed. São Paulo: Saraiva, 2012. 